\title{
CAN THE TAYLOR RULES EXPLAIN EXCHANGE RATE MOVEMENTS? EVIDENCE FROM CENTRAL AND EASTERN EUROPEAN COUNTRIES
}

This study investigates whether the Taylor rules can explain exchange rates for ten Central and Eastern European countries of the conditional distribution by employing a nonlinear quantile stationary test with the Fourier function, which combines the quantile unit root test with smooth unknown multiple breaks through the Fourier function and thus provide more accurate analysis results. We find that the choices and effectiveness of the monetary policies in Central Eastern European economies are highly influenced by the Taylor rules, and also influenced by external factors originating from the United States. Also, our findings point out the bilateral real exchange rates based on Taylor the rules convergence follow a non-linear way. Our results have important policy implications for Central and Eastern European Countries. breaks

Keywords: Taylor rules, quantile unit root with Fourier function, structural change, trend

JEL Classifications: C22, F36

DOI: $10.15611 /$ aoe.2018.2.02

\section{INTRODUCTION}

Since the 1980s, with the rapid development of the capital market and its derivatives market, the traditional monetary quantity theory has often been challenged, and the stable relationship between money supply and economic growth has become even more uncertain. Under the circumstances, the major Western countries have decided to give up money supply as a policy instrument. Instead, interest rate rules have gradually become the intermediate target of monetary rules. Taylor (1993) finds that among various fundamentals which affect price level and economic growth rate, the real interest rate is the only variable that can maintain the long-term stable relationship with price and economic growth. Therefore, Taylor believes that adjusting the real interest rate should be the main operation of the monetary

\footnotetext{
* School of Economics, Qingdao University, Qingdao, Shandong, China.

${ }^{* *}$ Department of Accounting and Information, Ling Tung University, Taichung, Taiwan.

**** Department of Finance, Ocean University of China, Qingdao, Shandong, China.
} 
authorities. The Taylor's rule is the monetary rule which mainly refers to the central bank - how to control the monetary policy of the country based on the target real interest rate and the target inflation rate. Although the Taylor rule is simple, it can well encapsulate the basic factors that affect the monetary policy in reality, as well as reflect the ultimate goal of monetary policy, i.e. the real output can be stabilized near the potential level in the short term and inflation could be effectively controlled over the long term.

The standard Taylor rule suggests that the nominal interest rate responds to the inflation rate and its target, the output gap and the equilibrium real interest rate. Many scholars have noted that the central bank has a favorable interest rate trend preferences (Clarida et al., 1999, 2000; Gerlach-Kristen, 2004; Consolo and Favero, 2009), so that the current interest rate not only depends on the output gap and inflation rate, but also depends on the last interest rate. The results show that the Taylor rule with a smoothing interest rate is better able to fit the actual observed policy than the original Taylor rule. In view of the forward-looking characteristics of monetary policy, the short-term interest rate is set as a function of the expected inflation gap and output gap, thus more truly reflecting the central bank's actual decisionmaking process.

Moreover, if a central bank targets the purchasing power parity (PPP) level of the exchange rate, the real exchange rate will also influence the nominal interest rate. It turns out that the Taylor rule of an open economy displays exchange rate behavior that is quite different from that in the traditional exchange rate model. The adoption of the Taylor rule by the central bank helps to establish effective communication channels and feedback mechanisms between the public and the central bank, guide the formation of public expectations and improve the effectiveness and transparency of monetary policy. The central bank would take a number of anti-inflation measures and achieve other objectives with the implementation of the Taylor rules to increase the credibility of monetary policy. The public can understand the inherent rationality of the role of monetary policy through the Taylor rules, so as to reduce the psychological uneasiness, avoid the disorder caused by the expected effect and ensure the smooth implementation of monetary policy. If employment is higher than the natural level of employment and real GDP will be below potential, the central bank will take action to deal with the economic issue. The greater the deviation from the target level, the stronger the response of monetary policy, so it is more beneficial for the ease of mitigating the adverse effects of macroeconomic volatility. 
During the period from the mid-1970s to the early 1980s, international economists mainly focused their attention on three major structural approaches to modeling exchange rates. There are the flexible-price monetary models, sticky-price monetary models, and portfolio balance models, although those models have been rejected by most researchers due to the result that none of the specifications could outperform the random walk model in predicting the exchange rate out-of-sample. Meese and Rogoff $(1983 \mathrm{a}, 1983 \mathrm{~b})$ put an end to the atmosphere of optimism in exchange rate economics by concluding that exchange rate determination models do not perform better than a random walk model out-of-sample. Mark (1995) used error correction methods to compare Purchasing Power Parity, Interest Rate Parity and monetary models with the random walk model with the Diebold-Mariano-West statistic (henceforth, DMW), and found that no systematic evidence of predictability could be found in the short term. Groen (2000) and Mark and Sul (2001) detect exchange rate predictability by using panel data. Kilian and Taylor (2003) find that exchange rates can be predicted from economic models at horizons of two to three years after taking into account the possibility of nonlinear exchange rate dynamics. Faust et al.(2003) find that the economic models consistently perform better using real-time data than revised data, though they do not perform better than the random walk. Cheung et al. (2005) examine the outof-sample performance of the interest rate parity, monetary, productivitybased and behavioral exchange rate models and conclude that none of the models consistently outperforms the random walk at any horizon.

This problem is avoided by extending the Taylor rule exchange rate models, the new strand of literature includes the endogenous of monetary policy using an interest rate rule as proposed by Taylor (1993). Comparing the traditional monetary model with the Taylor rule exchange rate model, we can find that the major shortcomings of traditional exchange rate models are in paying too little attention to the market's expectations of future values of the macroeconomic fundamentals (Engel and West, 2004, 2005, 2006; Bacchetta and van Wincoop, 2006; Engel et al., 2008). In particular, most standard monetary models fail to incorporate the endogeneity of monetary policy. Another possible reason for the failure of the economic exchange rate models is inadequate economic models for exchange rate forecasting. Kilian and Taylor (2003) argue that the underlying economic theory of exchange rate models is fundamentally sound. However, there are various nonlinearities in deviations of the spot exchange rate from economic fundamentals. Under the Taylor rule fundamental framework, Engel and 
West (2005) use their model to predict the exchange rate. They combine the monetary model, uncovered interest rate parity (UIP) and purchasing power parity (PPP) with the Taylor rule so as to derive the Taylor rule exchange rate model. This means that the Taylor rule exchange rate model relies on the stance true for PPP. PPP states that the exchange rates between currencies are in equilibrium when their purchasing power is the same in each of the two countries, if PPP holds true, the equilibrium exchange rate could be determined by the Taylor rule exchange rate model. Molodtsova and Papell (2009) find strong out-of-sample predictability for a group of major exchange rates. Engel et al. (2007) using a panel regression framework to test the exchange rate predictive ability find that the Taylor rule exchange rate performed better than standard monetary models and random walk model. Clarida and Waldman (2007) find a significant appreciation of exchange rates in response to positive inflation surprises for inflation targeting countries, which is one of the major predictions of these types of models. Mark (2007) considers the Taylor rule in interest rate reaction functions for Germany and the U.S. and estimates the real USDDEM exchange rate path assuming that the exchange rate is priced by uncovered interest rate parity, and provides evidence that the interest rate differential can be modeled as a Taylor rule differential and the real USDDEM exchange rate is linked to the Taylor rule fundamentals, which may provide a resolution for the exchange rate disconnect puzzle. Gali (2008) embeds the Taylor rules in open economy dynamic stochastic general equilibrium models and maps out the effects of monetary policy shocks on real and nominal exchange rates.

In this paper, we examine whether the Taylor rules can explain the exchange rates for Central and Eastern European countries. Since the Central and Eastern European countries joined the UEM (Union Economique et Monetaire) or the European Union (depending on the country), they are being increasingly explored by scholars. At the same time, price liberalization was accompanied by very high inflation rates in the earlier period, and then disinflated successfully after the exchange rate regimes switch. A standard approach to describe such monetary policy switching is to estimate a Taylor-like interest rate reaction function (Frömmel et al., 2011). The empirical literature concludes that the monetary policy interest rule (the Taylor rule) for most successful central banks in developed countries can be explained by such a reaction function, while relatively poor for transition economies (Clarida et al., 1998). Therefore, the features of CEECs' transition economies provide an interesting study of whether the 
Taylor rule can explain exchange rates movements. The reasons for studying Central and Eastern countries are as follows. First, they were centrally planned and underwent a rapid liberalization of prices and markets, and some markets suffered from high inflation. Second, most of the countries such as the Czech Republic, Hungary, Poland and the Slovak Republic focused on exchange rate targeting during the nineties and have mostly switched to inflation targeting after the 1997/98 Asian and Russian financial crisis. Third, and most important, the initial conditions for CEEC transition varied extensively, and they may be an important indicator in explaining the magnitude of deviations from the Taylor rules. Frömmel et al. (2011) explore monetary policy rules for Central and Eastern European Countries by explicitly accounting for changes in policy settings. The process of economic transition started in 1992 in the former Soviet Union complied with the liberalization of the foreign exchange markets and the provision of currency convertibility. These drastic steps resulted in initial deep undervaluation of the national currencies. We would like to compare CEECs in this paper as they are deeply influenced by the U.S. economy. The reason is that with the internationalization of Central and Eastern European countries and the continuous progress of global economic integration, and the United States as the world's largest economy, CEECs' economies are tightly connected with the world economy and thus with the economic condition of the U.S.

Usually, the Taylor rule relates to the short-term interest rate that specifies how the central bank should regulate its interest rate to the inflation rate to its past values, inflation and output gap. According to the Taylor rule, the central bank raises the target for the short-term nominal interest rate if inflation rises above its desired level and/or output is above potential output. This linear interest rate rule represents an optimal policy rule under the condition that the central bank minimizes a symmetric quadratic loss function (Svensson, 2000; Clarida et al.,1998, 2001). However, both theoretical and empirical studies exist to suggest that the central bank may follow a non-linear Taylor rule. Nobay and Peel (2003), Ruge-Murcia (2003), Dolado et al. (2005), Surico (2007), among others hold the view that if the central bank minimizes an asymmetric loss function in which negative and positive inflation and output-gap deviations are assigned different weights, then a non-linear Taylor rule is optimal. Engel and West (2005) use the Taylor rule model as an example of present value models in which asset prices (including exchange rates) will approach a random walk as the discount factor approaches one. Engel and West (2006) construct a "model- 
based" real exchange rate (RER) as the present value of the difference between home and foreign output gaps and inflation rates and find a positive correlation between the "model-based" rate and the actual RER. Because we know that the RER might be affected by the internal and external shocks generated by unexpected policies or political events, thus creating structural changes, they may be subject to considerable short-term variation. It is important to know whether the RER has any tendency to settle down to a long-run equilibrium level because the Taylor rules require that RER revolves around a constant or a time trend. If RER is found to be stationary using a unit root test with structural break(s), the effects of shocks such as real and monetary shocks that cause deviations around a mean value or deterministic trend are only temporary, then the Taylor rules are valid in the long run.

As for methodology, most of the studies have utilized conventional unit root tests such as the Augmented Dickey Fuller test (1981, ADF), the Phillips-Perron test (1988, PP), the Kwiatkowski et al. test (1992, KPSS) and time series cointegration, panel cointegration and error correction techniques to test the exchange rate determination. Unfortunately, they fail to reject the unit root hypothesis of the real exchange. The linear unit root test methodology assumes that in spite of the deviation situation, the process of urbanization moving to the equilibrium is linear and the velocity of adjustment is constant. However, if the nonlinear factors were neglected in the data generating process (DGP), we cannot receive the expected results. The linear model critically underestimates the velocity of adjustment of long-term equilibrium, and usually we accept the null hypothesis because of the low power of the traditional unit root test. The omission of some structural breaks is a possible cause of the traditional unit root tests failing to reject the null hypothesis for stationarity. It is well known that if the RER follows a nonlinear stationary process, then tests based on linear models such as the widely used ADF unit root models will be misspecified (Chortareas et al., 2002). Moreover, Sarno (2000) and Taylor and Peel (2000) also demonstrate that the adoption of linear stationary tests is inappropriate for the detection of a mean reversion if the true process of the data generation of the exchange rate is in fact a stationary non-linear process. Perron (1989) argued that if there is a structural break, the power to reject a unit root decreases when the stationary alternative is true and the structural break is ignored. Therefore we need to apply a technical method that could be of significance when structural breaks occur. The general method to account for breaks is to approximate them using dummy variables. However, 
this approach has several undesirable consequences. First, when the break dates are unknown, it is useful to have information regarding the presence or absence of a change to investigate the potential presence of a unit root, but these are usually not known and therefore need to be estimated. This introduces an undesirable pre-selection bias (see Maddala and Kim, 1998). Second, the models with dummy variables allow up to two breaks, otherwise, it will be result in information loss. Nunes et al. (1997), Lee and Strazicich (2003) and Kim and Perron (2009), among others, demonstrate that such tests suffer from serious power and size distortions due to the asymmetric treatment of breaks under the null and alternative hypotheses. Third, the use of dummies suggests sharp and sudden changes in trend or level. As a result, the test may reject the unit root null when the noise component is integrated but the trend is changing, leading to spurious evidence in favor of broken trend stationary. Besides, the traditional linear unit root test focused exclusively on stationary at the conditional mean of the data set, and cannot detect the heterogeneities among different quantiles of data distribution, thus we do not know the deep characteristics of data changes.

These arguments motivate the use of the recently developed non-linear quantile unit root with the Fourier function. Li and Park (2016) develop nonlinear Kapetanios-Shin-Snell quantile unit root test (KSS hereafter) to investigate stationarity in various quantiles. We extend their model with the Fourier function to capture possible structural breaks of an unknown form as a smooth process in the global and various quantiles. Several authors, including Gallant (1981) and Enders and Lee (2012), show that a Fourier approximation can control the unknown nature of the break(s). The authors argue that their testing framework requires only the specification of the proper frequency in the estimating equations. By reducing the number of estimated parameters they ensure that the tests have good size and power, irrespective of the time or shape of the break. One advantage of this Fourier approximation is that it is able to capture the essential characteristics of a series of breaks using low-frequency components, and the key feature is that we do not need to assume the break dates, the precise number of breaks and/or the exact form of the breaks are known priori. In particular, this test only works best in analyzing the global changing process, but deeply viewed different quantiles of sample data distribution.

This empirical study explores the link between an interest rate rule for monetary policy and the behavior of the RER. Whereas Engel and West (2006) use the model to explain the RER exclusively in terms of observable 
macroeconomic aggregates, we link these fundamentals with the transitory component of the exchange rate and also let both the transitory and the longterm equilibrium RER be influenced by random determinants. We base our analysis on a variant of the two-country Taylor rule model introduced by Engel and West (2006). It contributes to this line of research by determining the unit root process of RER of ten CEECs using the Taylor rules and the unit root test with a Fourier function proposed by Enders and Lee (2012). We analyze RER using Lagrange Multiplier (LM) unit root tests that allow for breaks in the trend and the level of a series at an unknown time. With this, the current research raises hopes to fill the existing gap in the literature. To the best of our knowledge, this study is the first that utilizes the unit root test with a Fourier function in RER based on the Taylor rules for CEECs. This empirical study contributes to the field of empirical research by determining whether the unit root process is a characteristic of the Taylor rules in CEECs.

The remainder of this empirical study is organized as follows. Section 2 describes the Taylor rules model. Section 3 presents the methodology of the nonlinear quantile unit root with the Fourier function. Section 4 presents the data used and discusses the empirical findings. Section 5 concludes the paper.

\section{THE TAYLOR RULE MODEL}

Taylor (1993) assumed a simple monetary policy rule to be followed by central banks. We examine the link between the exchange rates and a series of fundamental variables followed the Taylor rule. In general, a Taylor rule looks as follows:

$$
i_{t}^{*}=r^{*}+\pi_{t}+b_{1}\left(\pi_{t}-\pi^{*}\right)+b_{2} y_{t}^{g},
$$

where $i_{t}^{*}$ is the target for the short-term nominal interest rate, $r^{*}$ is the equilibrium level of the real interest rate, $\pi_{t}$ is the inflation rate, $\pi^{*}$ is the target level of inflation, and $y_{t}^{g}$ is the output gap, or percent deviation of actual real GDP from an estimate of its potential level. According to Taylor, central banks adjust the nominal interest rate based on the inflation gap and the output gap, and keep the real interest rate at the equilibrium real interest rate so that the real interest rate level can be neutral to avoid real interest rate fluctuations, then the economy grows steadily at the level of the target inflation rate, and ultimately achieve price stability and stable growth of the total output. 
Defined $u=r^{*}-b_{1} \pi^{*}, \lambda=1+b_{1}$, equation (1) can be expressed by

$$
i_{t}^{*}=u+\lambda \pi_{t}+b_{2} y_{t}^{g}
$$

Incorporating exchange rate into the original Taylor rule, we can get,

$$
i_{t}^{*}=u+\lambda \pi_{t}+b_{2} y_{t}^{g}+b_{3}\left(e_{t}-\bar{e}_{t}\right),
$$

where $e_{t}$ is the nominal exchange rate, $\bar{e}_{t}$ is the benchmark exchange rate from PPP, so $e_{t}-\bar{e}_{t}$ is the deviation from exchange rate.

Besides, some studies suggest that through adding a smoothing factor in the form of the interest rate (Clarida, 1998; Romer, 2011), the adjusted Taylor rule has the better policy implications. This is done by including a lagged interest rate differential in the form of a partial adjustment model:

$$
i_{t}=\rho i_{t-1}+(1-\rho) i_{t}^{*}+\varepsilon_{t},
$$

where $\rho$ is the smoothing factor, substituting (4) into (3):

$$
i_{t}=\rho i_{t-1}+(1-\rho)\left[b_{1} \pi_{t}+b_{2} y_{t}^{g}+b_{3}\left(e_{t}-\bar{e}_{t}\right)+\mu\right]+\varepsilon_{t} .
$$

Similarly, we assume that the foreign country also follows the Taylor rule but reacts differently from the home country. To derive the Taylor-rule based forecasting equation, we construct the interest rate differential by subtracting the interest rate reaction function for the foreign country from that for the U.S.:

$$
\begin{aligned}
i_{t}-i_{t}^{f}= & \rho\left(i_{t-1}-i_{t-1}^{f}\right)+(1-\rho) b_{1}\left(\pi_{t}-\pi_{t}^{f}\right)+(1-\rho) b_{2}\left(y_{t}^{g}-y_{t}^{g f}\right)+\ldots \\
& +(1-\rho)\left(b_{3}-b_{3}^{f}\right)\left(e_{t}-\bar{e}_{t}\right)+(1-\rho)\left(\mu-\mu^{f}\right)+\varepsilon_{t}-\varepsilon_{t}^{f}
\end{aligned}
$$

where $f$ denotes the foreign country.

Moreover, we shall assume that monetary authorities target the PPP level of the exchange rate:

$$
\bar{e}_{t}=p_{t}^{f}-p_{t}
$$

and the real exchange rate can be expressed as the sum of the nominal exchange rate and price difference of the two countries:

$$
q_{t}=e_{t}+p_{t}-p_{t}^{f} .
$$


Organizing the above equations, we get:

$$
\begin{gathered}
q_{t}=s\left(i_{t}-i_{t}^{f}\right)-s \rho\left(i_{t-1}-i_{t-1}^{f}\right)-s(1-\rho)\left[b_{1}\left(\pi_{t}-\pi_{t}^{f}\right)+\ldots\right. \\
\left.b_{2}\left(y_{t}^{g}-y_{t}^{g f}\right)\right]-s(1-\rho)\left(\mu-\mu^{f}\right)-s\left(\varepsilon_{t}-\varepsilon_{t}^{f}\right),
\end{gathered}
$$

where $s=\frac{1}{(1-\rho)\left(b_{3}-b_{3}^{f}\right)}$.

This equation implies that the real exchange rate can be affected by interest rate differentials, output gap differentials and inflation differentials.

\section{NONLINEAR QUANTILE UNIT ROOT TEST WITH THE FOURIER FUNCTION}

Li and Park (2016) developed the nonlinear unit root test of Kapetanios et al. (2003) on quantile regression framework than the ordinary least squares (OLS) estimator. The simulation results show that it has much more power than the standard ADF test when the data follow a different distribution. Another advantage of the test is that it allows for different adjustment mechanism towards the long-term equilibrium at different quantiles. According to Kapetanios et al. (2003), the KSS test is based on detecting the presence of non-stationarity against a nonlinear but globally stationary exponential smooth transition autoregressive (ESTAR) process. The model form is as follows:

$$
\Delta Y_{t}=\gamma Y_{t-1}\left[1-\exp \left(-\varpi Y_{t-1}^{2}\right)\right]+\varepsilon_{t},
$$

where $Y_{t}$ is the data series of interest, $\varepsilon_{t}$ is an i.i.d. error with zero mean and constant variance, and $\varpi \geq 0$ is the transition parameter of the ESTAR model and governs the speed of transition. Under the null hypothesis $Y_{t}$ follows a linear unit root process, but $Y_{t}$ follows a nonlinear stationary ESTAR process under the alternative. One shortcoming of this framework is that the parameter $\gamma$ is not identified under the null hypothesis. Kapetanios et al. (2003) used a first-order Taylor series approximation for $\left[1-\exp \left(-\varpi Y_{t-1}^{2}\right)\right]$ under the null hypothesis $\varpi=0$ and then approximated Equation (10) by using the following auxiliary regression:

$$
\Delta Y_{t}=\xi+\delta Y_{t-1}^{3}+\sum_{i=1}^{k} b_{i} \Delta Y_{t-i}+v_{t}
$$


where $k$ represents the frequency. In this framework the null hypothesis and alternative hypotheses are expressed as $\delta=0$ (non-stationarity) against $\delta<0$ (non-linear ESTAR stationarity). The system of the KSS equations with a Fourier function that we estimate is of the form:

$$
\begin{gathered}
\Delta Y_{t}=\alpha_{1}+\beta_{1} Y_{t-1}^{3}+\sum_{j=1}^{k} \theta_{j} \Delta Y_{t-j}+a_{1} \sin \left(\frac{2 \pi k t}{T}\right)+b_{1} \cos \left(\frac{2 \pi k t}{T}\right)+\varepsilon_{t}, \\
t=1,2, \ldots, T,
\end{gathered}
$$

where $k$ represents the frequency for the approximation. It is important to note that the real exchange rate may present asymmetric characteristic in different distribution, then we assume that the real exchange rate data generating process can be written as Equation (4) based on quantile function form:

$$
\begin{gathered}
Y_{t}=\alpha(\tau)+c(\tau) t+\beta(\tau) Y_{t-1}^{3}+ \\
+\sum_{i=1}^{q} \gamma_{i}(\tau) \Delta Y_{t-1}+\theta_{1} \sin \left(\frac{2 \pi k t}{T}\right)+\theta_{2} \cos \left(\frac{2 \pi k t}{T}\right)+\varepsilon_{t}
\end{gathered}
$$

where $\tau$ stands for quantiles [0.1,0.9]. In order to construct a statistic test, we rewrite the above function as a reduced form as follows:

$$
Q_{\lambda_{t}}\left(\tau \mid \varsigma_{t-1}\right)=\rho_{1}(\tau) \lambda_{t-1}^{3}+\sum_{i=1}^{m} \rho_{i+1}(\tau) \Delta \lambda_{t-i}+\varepsilon_{t},
$$

where $Q_{\lambda_{t}}\left(\tau \mid \varsigma_{t-1}\right)$ is the $\tau_{t h}$ quantile of $\lambda_{t}$ condition on the past information set, $\varsigma_{t-1}$. Optimum lags are selected by the Bayesian information criterion (BIC) or by Schwarz criterion.

The coefficients of $\rho_{1}(\tau), \rho_{2}(\tau), \ldots, \rho_{k+1}(\tau)$ are estimated by minimizing the sum of the asymmetrically weighted absolute deviations:

$$
\begin{aligned}
\min \sum_{t=1}^{n}( & \left.\tau-I\left(e_{t}<\alpha_{0}(\tau)+\alpha_{1}(\tau) e_{t-1}+\sum_{k=1}^{l} \alpha_{1+k}(\tau) \Delta e_{t-k}\right)\right) \mid e_{t}-\ldots \\
& \left.-\alpha_{0}(\tau)+\alpha_{1}(\tau) e_{t-1}+\sum_{k=1}^{l} \rho_{1+k}(\tau) \Delta e_{t-k}\right)
\end{aligned}
$$

where $l$ is lag order, and $I=1$ if $e_{t}<\alpha_{0}(\tau)+\alpha_{1}(\tau) e_{t-1}+\sum_{k=1}^{l} \alpha_{1+k}(\tau) \Delta e_{t-k}$ and $I=0$, otherwise. As suggested by Koenker and Xiao (2004), after solving Equation 
(15), we can test the stochastic properties of $e_{t}$ within the $\tau_{t h}$ quantile by using the following $t$ ration statistic:

$$
t_{n}\left(\tau_{i}\right)=\frac{\hat{f}\left(F^{-1}\left(\tau_{i}\right)\right)}{\sqrt{\tau_{i}\left(1-\tau_{i}\right)}}\left(E_{-1}^{\prime} P_{X} E_{-1}\right)^{1 / 2}\left(\hat{\alpha}_{1}\left(\tau_{i}\right)-1\right),
$$

where $E_{-1}$ is the vector of lagged dependent variable $e_{t-1}, P_{X}$ is the projection matrix onto the space orthogonal to $X=\left(1, \Delta e_{t-1}, \ldots, \Delta e_{t-k}\right)$ and $\hat{f}\left(F^{-1}\left(\tau_{I}\right)\right)$ is a consistent estimator of $f\left(F^{-1}\left(\tau_{I}\right)\right)$. Koenker and Xiao (2004) suggest that it can be expressed as:

$$
\hat{f}\left(F^{-1}\left(\tau_{I}\right)\right)=\frac{\left(\tau_{i}-\tau_{i-1}\right)}{x^{\prime}\left(\beta\left(\tau_{i}\right)-\beta\left(\tau_{i-1}\right)\right)}
$$

where $\beta\left(\tau_{i}\right)=\left(\alpha_{0}\left(\tau_{i}\right), \alpha_{1}\left(\tau_{i}\right), \alpha_{2}\left(\tau_{i}\right), \ldots, \alpha_{1+k}\left(\tau_{i}\right)\right), \tau_{i} \in[0.1,0.9]$. As can be seen, when using $t_{n}\left(\tau_{i}\right)$ statistics we are able to test the unit root hypothesis in each quantile while ADF and other conventional unit root tests examine the unit root only on the conditional central tendency.

To assess the unit root behavior over a range of quantiles, Koenker and Xiao (2004) recommend the following Quantile Kolmogorov-Smirnov (QKS) test:

$$
Q K S=\sup _{\tau_{i} \in[\min , \max ]}\left|t_{n}\left(\tau_{i}\right)\right| .
$$

In this paper we construct the QKS statistics by choosing maximum $t_{n}\left(\tau_{i}\right)$ and QKS test statistics are nonstandard and depend on nuisance parameters. Hence, to derive critical values for the above mentioned test we implement the re-sampling procedures of Koenker and Xiao (2004) as follows.

Firstly, we run following $k$-order autoregression by the ordinary least square method:

$$
\Delta e_{t}=\sum_{k=1}^{l} \rho_{k} \Delta e_{t-k}+\varepsilon_{t} .
$$

Secondly, we save fitted values $\Delta \hat{e}_{t}=\sum_{k=1}^{l} \hat{\alpha}_{k} \Delta \hat{e}_{t-k}$ and residuals $\hat{\varepsilon}_{t}$ and then create bootstrap residuals $\left\{\hat{\varepsilon}_{t}^{b}\right\}$ with replacement from the centered residuals $\hat{\varepsilon}_{t}=\hat{\varepsilon}_{t}-\frac{1}{n-1} \sum_{t=1+l}^{n} \hat{\varepsilon}_{t}$. 
Thirdly, we calculate the bootstrap sample of observations $e_{t}^{b}$ as follows:

$$
e_{t}^{b}=e_{t-1}^{b}+\Delta e_{t}^{b},
$$

where $\Delta e_{t}^{b}=\sum_{k=1}^{k} \hat{\alpha}_{k} \Delta e_{t-k}^{b}+\varepsilon_{t}^{b}, \Delta e_{j}^{b}=\Delta e_{j}, j=1,2, \ldots, l, e_{1}^{b}=e_{1}$.

We construct the $\alpha_{0}(\tau)$ and $\alpha_{1}(\tau)$ based on Equation (13), $t_{n}(\tau)$ statistics based on Equation (17) and QKS statistics based on Equation (18), and the QKS tests would be used to judge whether the data contains a unit root or not in different quantiles.

\section{DATA AND EMPIRICAL FINDINGS}

We investigate whether the Taylor rule can explain exchange rate movements in ten selected Central and Eastern European countries by using the quantile unit root with the Fourier function based on the KSS test. Our monthly data covers the time span from January 1994 to December 2016. During this period, Central and Eastern European countries undertook a number of reforms, such as starting their liberalization programs and transition to market economies and so on. This empirical study covers ten countries: Bulgaria, Croatia, the Czech Republic, Estonia, Hungary, Latvia, Lithuania, Poland, Romania and the Slovak Republic versus the United States. For the interest rates, we consider the choice of the interest rate measure robust to our estimates and base our choice on the availability of the data, we use the money market rate or deposit rate, specifically, Bulgaria (LEONIA reference rate), Croatia(short-term rate determined on the Zagreb Money Market), Czech Republic(money market rate), Estonia(lowest rate on household deposits), Hungary(simple arithmetic rate offered by banks on deposits), Latvia (weighted average rate on overnight loans in national currency transacted in the interbank market),Lithuania (money market rate), Poland(money market rate), Romania(daily average rate on deposits between commercial banks in national currency), the Slovak Republic (money market rate). The sampling period is chosen for two main reasons: first, it is the source employed by the European Central Bank; second, it offers homogeneous data for all European countries; besides, the choice of a monthly frequency allows us to use exogenously defined periods of crises.

Furthermore, when measuring the output gap variable, many countries release quarterly or annual data for GDP, so in order to avoid the information loss of real-time data and be consistent with the monthly frequency, we choose the seasonally adjusted Industrial Production Index 
(IPI) as a proxy indicator of output. Generally, the way to calculate the potential output is a difficult task and would affect the results seriously if calculated wrongly. However, most studies use a filter to calculate the potential output and output gap. If we assume the original series to exhibit a deterministic trend, we can measure the potential output by the HodrickPrescott filter of the IPI. The output gap is then computed as the deviation of the logarithm of the actual industrial production from its HP trend.

Inflation is measured by the monthly percentage change in the seasonally adjusted Harmonized Consumer Price Index (HCPI). Judd and Rudebusch (1998) base their inflation rates on different price indices and conclude that the estimation is not very sensitive to different measures of inflation. Kozichi (1999), Bodenstein et al. (2008), Mehra and Sawhney (2010), Airaudo and Zanna (2012) come to the opposite conclusion that the recommendations given by the Taylor rule are not robust to the inflation measures. We will base our estimates on a single index, the Harmonized Index of Consumer Prices (HICP) from Eurostat.

Lastly, when calculating the bilateral real exchange rates based on the Taylor rules, we first calculate the ratio of the price level US and the price levels for Central and Eastern European countries, then we use the ratios minus the inflation differentials, interest rate differentials and output gap differentials, to get the bilateral real exchange rates of Central and Eastern European countries versus the US based on the Taylor rules.

Table 1 provides a summary statistics of the real exchange rates for ten Central and Eastern European countries. The maximum value of RER is 121.920 for Poland, the Slovak Republic has the largest standard deviation, indicating that real exchange rate fluctuated the most in the Slovak Republic. The coefficients of skewness of all countries except Croatia, show that the real exchange rates are flatter to the right compared to the normal distribution, except for Croatia. We can also observe that the coefficients of kurtosis for some data sets exceed 3 associated with a normal distribution for Estonia, Latvia, Lithuania and Poland, meaning that the empirical distributions of these samples have fat tails. The Jarque-Bera test results indicate that the sample data are normally distributed except for Poland.

As a comparison, several univariate unit root tests, ADF, PP and the KPSS, are employed to test the null hypothesis of a unit root in bilateral RERs based on the Taylor rules for the ten CEECs under study. Based on the results from Table 2, we find that with the exceptions of Estonia, Lithuania and Poland, the null hypothesis of a unit root cannot be rejected at the $10 \%$ significance level for the ADF statistics. The results from PP test show that the real exchange rates contain a unit root except for Estonia, Latvia and 
Table 1

Summary statistics of real exchange rates (Jan 1994 - Dec 2016)

\begin{tabular}{l|c|r|r|r|r|r|c}
\hline \multicolumn{1}{c|}{ Country } & \multicolumn{1}{c|}{ Mean } & \multicolumn{1}{c|}{ Max. } & \multicolumn{1}{c|}{ Min. } & \multicolumn{1}{c|}{ Std. } & \multicolumn{1}{c}{ Skewness } & Kurtosis & \multicolumn{1}{c}{ J-B } \\
\hline Bulgaria & 81.346 & 104.950 & 35.020 & 18.911 & -0.602 & 2.251 & $23.155^{* * *}$ \\
\hline Croatia & 94.153 & 104.620 & 86.270 & 4.214 & 0.431 & 2.603 & $10.322^{* * *}$ \\
\hline $\begin{array}{l}\text { Czech } \\
\text { Republic }\end{array}$ & 80.929 & 111.300 & 53.110 & 15.749 & -0.192 & 1.747 & $19.744^{* * *}$ \\
\hline Estonia & 88.578 & 90.835 & 41.510 & 14.477 & -1.017 & 3.463 & $50.087^{* * *}$ \\
\hline Hungary & 86.748 & 115.390 & 65.170 & 12.743 & -0.211 & 1.753 & $19.932^{* * *}$ \\
\hline Latvia & 90.800 & 110.250 & 57.100 & 11.688 & -0.894 & 3.019 & $36.851^{* * *}$ \\
\hline Lithuania & 87.026 & 106.420 & 40.310 & 16.479 & -1.329 & 3.835 & $89.352^{* * *}$ \\
\hline Poland & 91.812 & 121.920 & 67.470 & 10.520 & -0.241 & 3.022 & 2.686 \\
\hline Romania & 88.018 & 119.340 & 44.540 & 16.378 & -0.623 & 2.451 & $21.372^{* * *}$ \\
\hline $\begin{array}{l}\text { Slovak } \\
\text { Republic }\end{array}$ & 77.437 & 105.870 & 47.920 & 20.955 & -0.059 & 1.321 & $32.561^{* * *}$ \\
\hline
\end{tabular}

Note: 1. Std denotes standard deviation, and J-B denotes the Jarque-Bera test for normality.

2. *** indicates significance at the $1 \%$ level.

Source: authors' calculations.

Table 2

Univariate unit root test for real exchange rates

\begin{tabular}{l|l|l|l|l|l|l}
\hline \multirow{2}{*}{ Country } & \multicolumn{3}{|c|}{ Levels } & \multicolumn{3}{c}{ First Differences } \\
\cline { 2 - 6 } & \multicolumn{1}{|c|}{ ADF } & \multicolumn{1}{|c|}{ PP } & \multicolumn{1}{c}{ KPSS } & \multicolumn{1}{c}{ ADF } & \multicolumn{1}{c}{ PP } & \multicolumn{1}{c}{ KPSS } \\
\hline Bulgaria & $-2.009[3]$ & $-1.784[6]$ & $1.791[14]^{* * *}$ & $-13.376[2]^{* * *}$ & $-14.921[4]^{* * *}$ & $0.313[44]$ \\
\hline Croatia & $-2.082[1]$ & $-1.930[5]$ & $0.984[14]$ & $-14.369[0]^{* * *}$ & $-14.219[9]^{* * *}$ & $0.176[7]^{* * *}$ \\
\hline Czech Republic & $-1.687[0]$ & $-1.687[0]$ & $1.682[14]$ & $-14.491[0]^{* * *}$ & $-14.467[5]^{* * *}$ & $0.308[0]$ \\
\hline Estonia & $-4.734[1]^{* * *}$ & $-5.758[7]^{* * *}$ & $1.751[14]^{* * *}$ & $-12.781[0]^{* * *}$ & $-12.641[3]^{* * *}$ & $1.173[6]^{* * *}$ \\
\hline Hungary & $-1.639[1]$ & $-1.545[3]$ & $1.402[14]^{* * *}$ & $-13.105[0]^{* * *}$ & $-12.850[8]^{* * *}$ & $0.126[4]^{* * *}$ \\
\hline Latvia & $-2.493[1]$ & $-3.135[5]^{* *}$ & $1.395[14]^{* * *}$ & $-10.993[0]^{* * *}$ & $-10.970[3]^{* * *}$ & $0.448[6]^{*}$ \\
\hline Lithuania & $-3.949[2]^{* * *}$ & $-4.758[17]^{* * *}$ & $1.555[14]^{* * *}$ & $-11.638[0]^{* * *}$ & $-11.341[12]^{* * *}$ & $1.041[4]^{* * *}$ \\
\hline Poland & $-2.831[1]^{*}$ & $-2.447[1]$ & $0.987[14]^{* * *}$ & $-11.576[0]^{* * *}$ & $-11.080[11]^{* * *}$ & $0.177[2]^{* * *}$ \\
\hline Romania & $-1.871[1]$ & $-1.725[6]$ & $1.486[14]^{* * *}$ & $-12.051[0]^{* * *}$ & $-11.976[2]^{* * *}$ & $0.137[5]$ \\
\hline Slovak Republic & $-1.071[1]$ & $-1.054[5]$ & $1.843[14]^{* * *}$ & $-12.006[0]^{* * *}$ & $-12.008[1]^{* * *}$ & $0.287[6]$ \\
\hline
\end{tabular}

Note: $* * * * *$ and $*$ indicate significance at the $1 \%, 5 \%$ and $10 \%$ levels, respectively. The numbers in parentheses indicate the lag orders selected based on the recursive t-statistic, as suggested by Perron (1989). The numbers in the brackets indicate the truncation for the Bartlett kernel, as suggested by the Newey-West test (1987).

Source: authors' calculations.

Lithuania. However, the results of the KPSS test cannot reject the stationary process hypothesis except for Croatia and the Czech Republic, meaning that the real exchange rate in Croatia and the Czech Republic are stationary, and others contain unit root. Based on these linear unit root test 
Table 3

Results of unit root test for each quantile

\begin{tabular}{|c|c|c|c|c|c|c|c|c|c|c|}
\hline Country & $\tau$ & 0.1 & 0.2 & 0.3 & 0.4 & 0.5 & 0.6 & 0.7 & 0.8 & 0.9 \\
\hline \multirow{4}{*}{ Bulgaria } & $\alpha_{0}(\tau)$ & $-1.166^{* * *}$ & $-0.677 * * *$ & $-0.446^{* * *}$ & $-0.242 * *$ & -0.065 & 0.153 & $0.347^{* * *}$ & $0.794^{* * *} *$ & $1.281^{* * *}$ \\
\hline & $\alpha_{1}(\tau)$ & -0.972 & -0.768 & -0.719 & $-5.115 * * *$ & $-5.210 * * *$ & $-3.838 * * *$ & $-2.977 * *$ & $-14.140 * * *$ & $-15.505 * * *$ \\
\hline & \multicolumn{10}{|c|}{ QKS for quantiles of $10-90 \% \quad \mathbf{1 5 . 5 0 5}^{* *}$} \\
\hline & \multicolumn{10}{|c|}{ Optimal Frequency $\mathbf{0 . 5}$} \\
\hline \multirow{4}{*}{ Croatia } & $\alpha_{0}(\tau)$ & $-0.967 * * *$ & $-0.572 * * *$ & $-0.341 * * *$ & $-0.182 * *$ & -0.001 & $0.184^{* *}$ & $0.436^{* * * *}$ & $0.603 * * *$ & $1.041^{* * *}$ \\
\hline & $\alpha_{1}(\tau)$ & -1.300 & -1.769 & $-2.318 *$ & $-3.229 * *$ & $-2.426^{*}$ & -2.282 & $-3.335 * *$ & $-2.747 * *$ & $-2.287 *$ \\
\hline & \multicolumn{10}{|c|}{ QKS for quantiles of $10-90 \% \quad 3.315$} \\
\hline & \multicolumn{10}{|c|}{ Optimal Frequency $\mathbf{1 . 0}$} \\
\hline \multirow{4}{*}{ Czech Republic } & $\alpha_{0}(\tau)$ & $-1.349 * * *$ & $-0.731 * * *$ & $-0.416 * * *$ & -0.128 & 0.026 & $0.238 * *$ & $0.521 * * *$ & $0.956^{* * *}$ & 1.380 \\
\hline & $\alpha_{1}(\tau)$ & $-7.314 * * *$ & $-3.386^{* *}$ & $-4.800 * * *$ & $-5.929 * * *$ & $-7.285^{* * *}$ & $-4.676 * * *$ & $-4.061 * * *$ & -1.155 & 2.796 \\
\hline & \multicolumn{10}{|c|}{ QKS for quantiles of $10-90 \% 7.314 * *$} \\
\hline & \multicolumn{10}{|c|}{ Optimal Frequency $\mathbf{0 . 7}$} \\
\hline \multirow{4}{*}{ Estonia } & $\alpha_{0}(\tau)$ & $-0.808 * * *$ & $-0.529 * * *$ & $-0.347 * * *$ & $-0.168 * *$ & -0.019 & 0.122 & $0.334^{* * *}$ & $0.589 * * *$ & $0.901 * * *$ \\
\hline & $\alpha_{1}(\tau)$ & -2.882 & -1.946 & -2.201 & -2.32 & -2.512 & -2.511 & -1.73 & -2.4 & -1.486 \\
\hline & \multicolumn{10}{|c|}{ QKS for quantiles of $10-90 \% 2.882$} \\
\hline & \multicolumn{10}{|c|}{ Optimal Frequency $\mathbf{0 . 1}$} \\
\hline \multirow{4}{*}{ Hungary } & $\alpha_{0}(\tau)$ & $-1.425^{* * *}$ & $-0.960 * * *$ & $-0.537 * * *$ & $-0.290 * *$ & -0.077 & $0.323^{*} *$ & $0.538^{* * * *}$ & $1.001 * * *$ & $1.791 * * *$ \\
\hline & $\alpha_{1}(\tau)$ & -1.606 & $-2.968 * *$ & $-4.034 * * *$ & $-5.662 * * *$ & $-4.577 * * *$ & $-4.480 * * *$ & $-4.687 * * *$ & $-3.510 * * *$ & $-3.190 * *$ \\
\hline & \multicolumn{10}{|c|}{ QKS for quantiles of $10-90 \% \mathbf{5 . 6 6 2} * * *$} \\
\hline & \multicolumn{10}{|c|}{ Optimal Frequency $\mathbf{0 . 8}$} \\
\hline
\end{tabular}




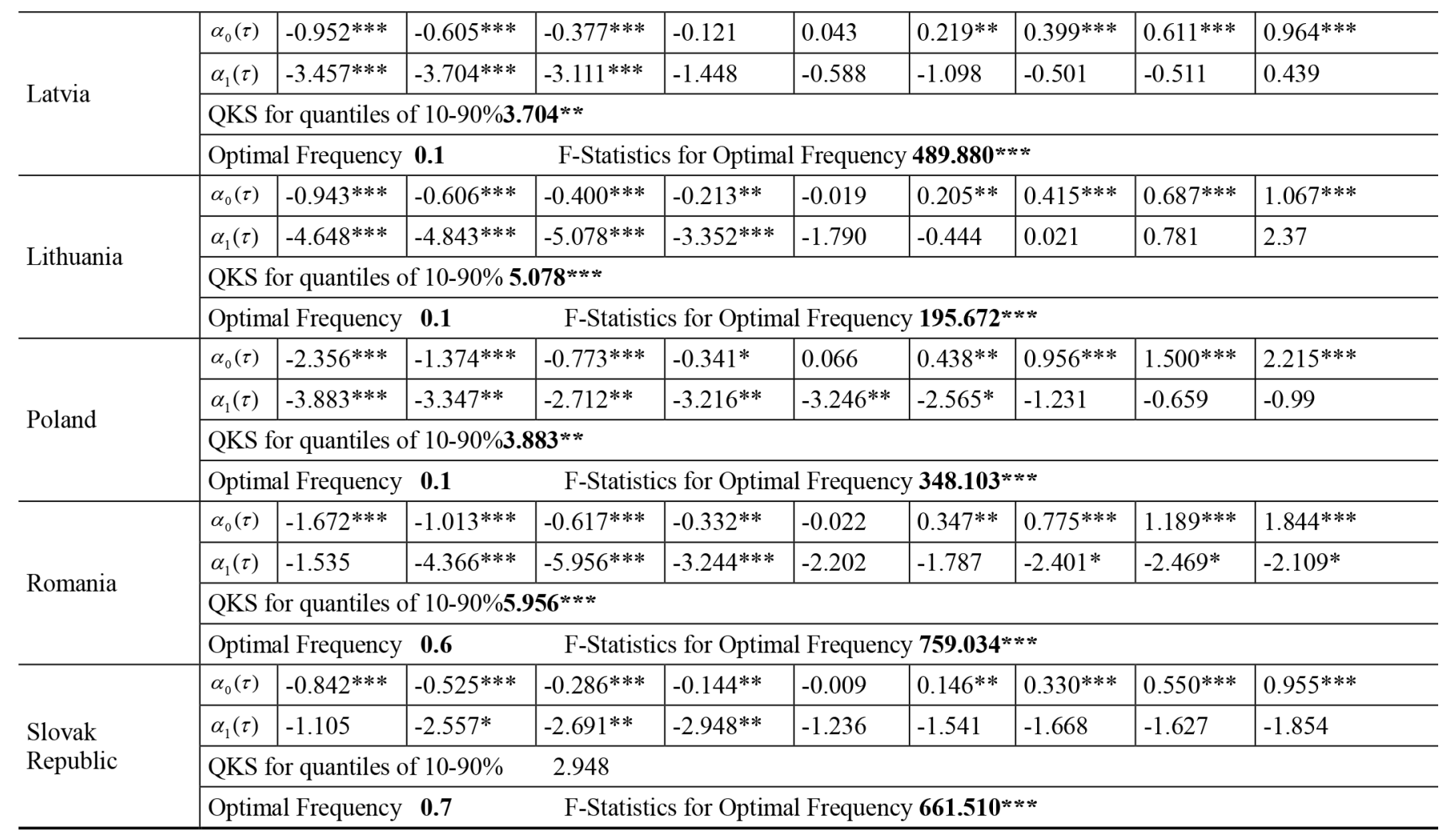

Source: authors' calculations. 

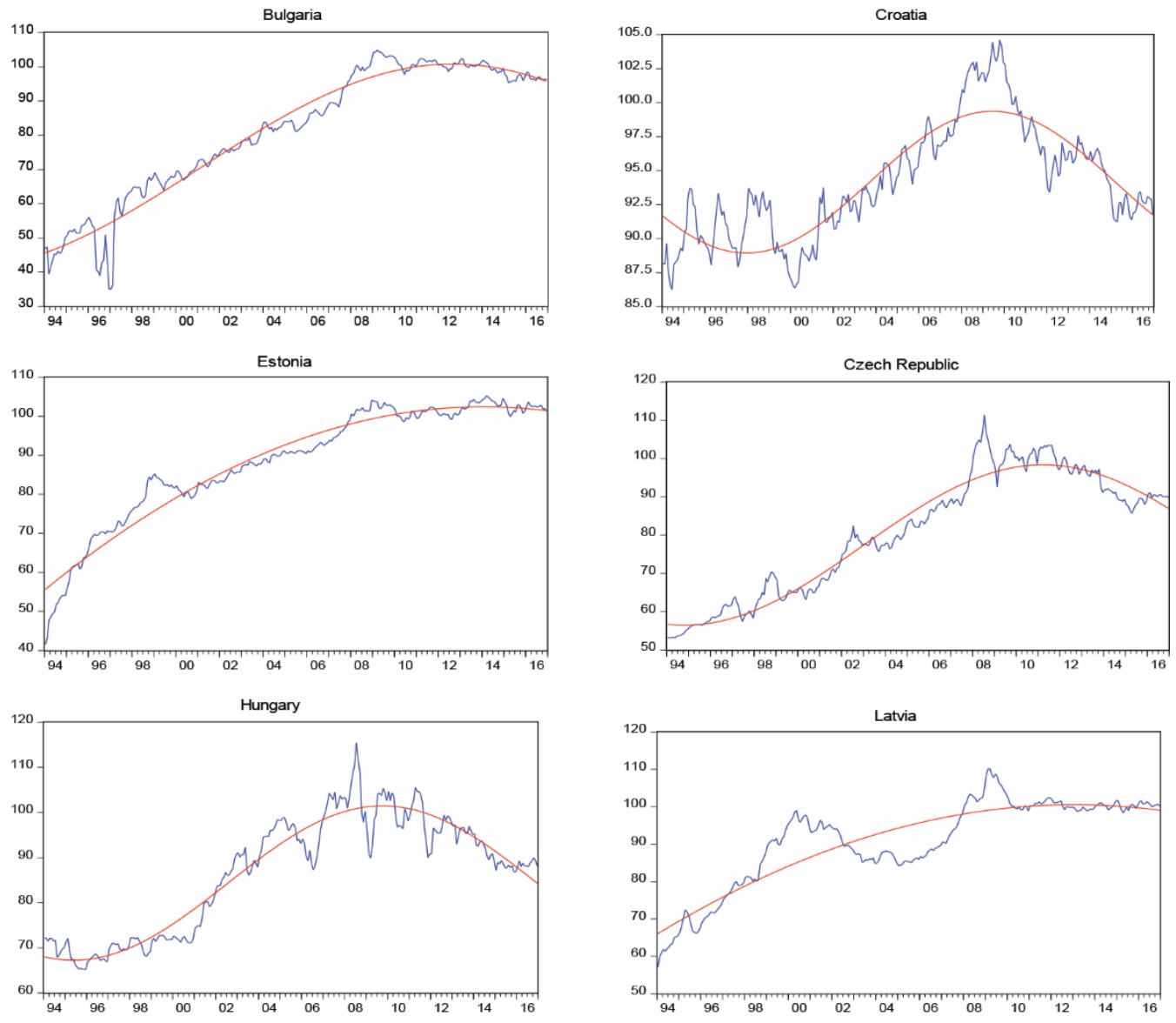

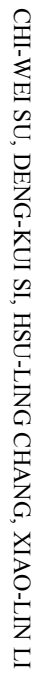



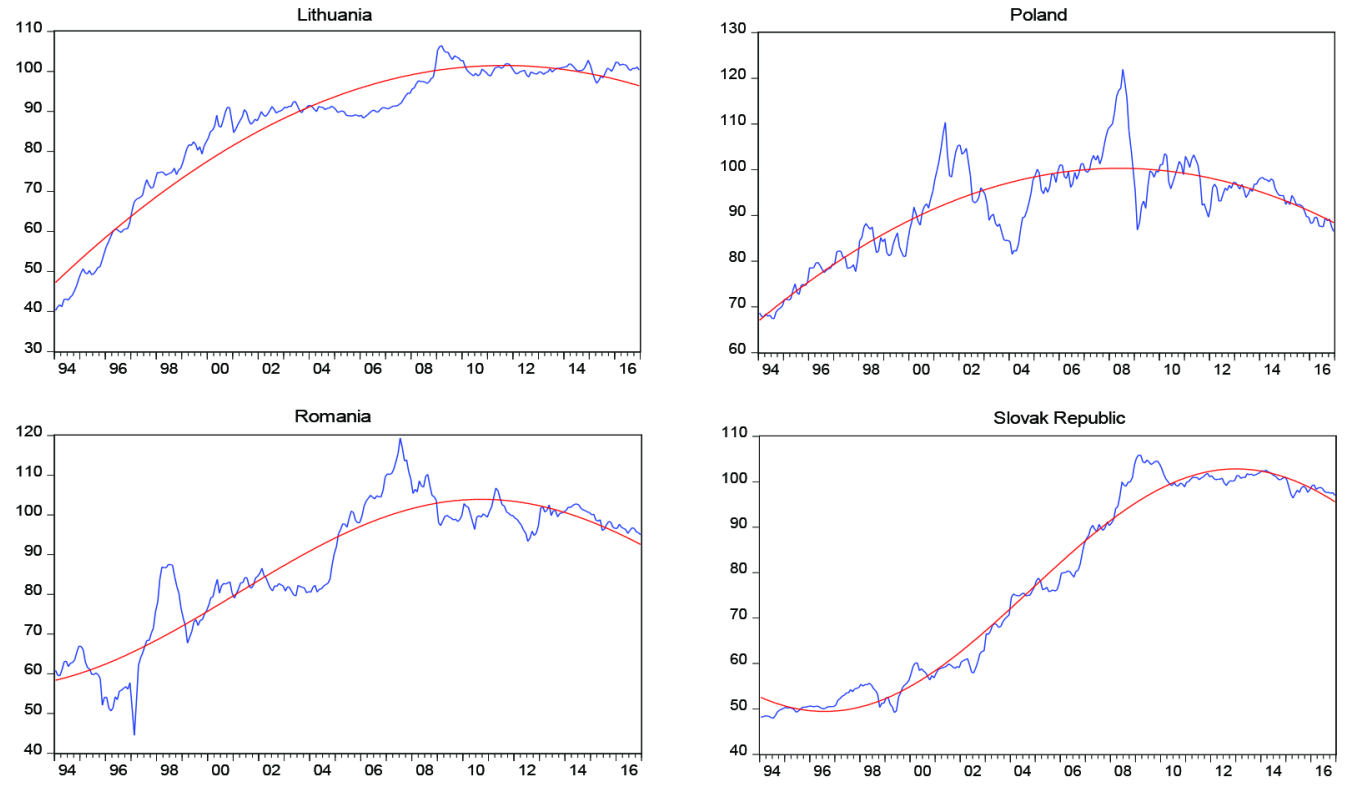

Figure 1. Real exchange rate convergence and fitted nonlinearities

Source: authors' calculations. 
results, we cannot reach a general agreement on the stationarity of these Central and Eastern European real exchange rates.A possible reason for getting mixed and ambiguous results from the standard linear unit root tests is that we ignore the feature of structural breaks. As Perron (1989) pointed out, if there is a structural break, its omission would probably reduce the ability to reject a unit root when the stationary alternative is true. Accordingly, it appears sensible to allow for structural breaks in testing for a unit root (and/or stationarity). To address this problem, we employ a newly developed quantile-based KSS unit root test with the Fourier function to reexamine the stationary of bilateral real exchange rates based on the Taylor rules. As shown in Table 3, the values of $\alpha_{0}(\tau)$ present an almost monotonically rising pattern for all the countries, which indicates that the larger values of $\tau$, the bigger the values of $\alpha_{0}(\tau)$ across all these countries. Moreover, when $\tau=0.5$, the magnitude of shock is not significantly different from zero at the $10 \%$ level for almost all countries. We know that $\alpha_{0}(\tau)$ denotes the size of the observed shock within each $\tau$ quantile that hits the real exchange rates; when $\alpha_{0}(\tau)$ is less (more) than zero, it means that the shock is negative (positive). To gain more insight, we also display the time paths of inflation rate and the estimated Fourier function in Figure 1. We can clearly observe structural shifts in the trend of the data.

Finally, we look at the estimated values of $\alpha_{1}(\tau)$ and QKS statistic reported in Table 3, which are the key to making a judgment of stationarity of real exchange rates in each of the quantiles. Generally speaking, the real exchange rate has a unit root in some quantiles, but is stationary in others. According to the $p$-values for the QKS statistic, we find that the null hypothesis of unit root is rejected for all the countries except for Croatia, Estonia and the Slovak Republic. In global terms, these results supporting real exchange rates stationarity and the global mean reversion results also imply that even if the shocks to real exchange rates are respectively short, they are long-lived in small and large quantiles. In particular, in Latvia, Lithuania and the Slovak Republic, the $\alpha_{1}(\tau)$ coefficients are significant at low quantiles $\tau \in[0.1,0.3], \tau \in[0.1,0.4]$ and $\tau \in[0.2,0.4]$, indicating that when the real exchange rates are at low levels, they are stationary, but contain a unit root when they stay at a relatively high level, which implies that the government would take corresponding measures to intervene the high exchange rate. For Croatia and Romania, the $\alpha_{1}(\tau)$ coefficients are significant in quantiles $\tau \in[0.3,0.5], \tau \in[0.2,0.4]$ and $\tau \in[0.7,0.9]$, respectively. This 
implies that when the real exchange rates are extremely low or high, then the real rate would contain a unit root with the feature of random walk. For Bulgaria and Poland the $\alpha_{1}(\tau)$ coefficients are significant during $\tau \in[0.4,0.9]$ and $\tau \in[0.1,0.6]$, respectively, which indicates that the real exchange rates present stationary behavior during the medium quantiles. Note that none of the quantiles of the real exchange rate is significant for Estonia, meaning that the real exchange rate in Estonia follows the random walk process in global terms and each quantile, thus the exchange rate cannot be explained by the Taylor rule, rather it follows a random walk process.

It is worth noting that the dynamic behaviors of real exchange rates for the selected ten Central and Eastern European countries are asymmetric, meaning that they are far from being persistent in some quantiles, while containing a unit root in the other quantiles. The different effects of real exchange rate shocks depending on the size of a shock might be caused by asymmetric monetary policy. We also find that these selected countries have already taken a series of policy reforms, such as exchange rate regime reform and some innovations in monetary policy. We investigate the role of the exchange rate by examining the Taylor rules of the central bank and the extent to which the interest rate-setting behavior has accounted for exchange rate developments. When evaluating monetary policy rules, it is important to consider the conversion of exchange rate regimes. The interest rate setting behavior of the central bank and to what extent the interest setting behavior has taken exchange rate developments into account, is a valuable procedure to analyze the role of the exchange rate. Since the exchange rate regime sometimes moves substantially against some of the other currencies, it is important that such fluctuations should also be taken into account. For example, the Czech Republic, Hungary, Poland and Slovakia switched from fixed to flexible exchange rate regimes during the sample period and then chose inflation targeting as a monetary strategy. Hungary and the Czech Republic have shifted the role of the exchange rate in their interest rate setting behavior in line with their official policy shifts from fixed to flexible exchange rate regimes. Poland gives the strongest results for pure inflation targeting, which are also in line with the official announcements, while the results for Slovakia may reflect the discretionary stance of the central bank as observed by the members of the central bank themselves. Romania officially declared managed floating exchange rate regimes during the entire sample period but Romania never officially declared any monetary policy strategy and pursued different forms of monetary targeting, later moving to 
a two-pillar strategy akin to the strategy of the European Central Bank. Apart from Romania, which officially claimed to have had managed floating regimes during the total sample period, the CEECs have successively moved from rather fixed to more flexible exchange rate regimes by widening the exchange rate bands over time. Thus, such a strategy of monetary policy has made the role of exchange rate decline over time. Nevertheless the exchange rate may still have been of implicit significance in monetary policy strategies.

An important point needs to be noted that the nonlinear quantile stationary test with a Fourier function employed in our study provides evidence favoring that the Taylor rules can explain exchange rates movements for the seven CEECs under study. The major policy implication that emerges from this study is that the Taylor rules can be used to forecast exchange rate movements for these seven selected Central and Eastern European countries. The public can predict the exchange rate movements and the dynamic tendency according to interest rate differentials, output gap differential and inflation differentials. Our results also indicate that strict inflation targeting implies the vigorous use of the direct exchange rate channel for stabilizing inflation on a short horizon. In contrast, flexible inflation targeting ends up stabilizing inflation on a longer horizon, and thereby also stabilizes RERs and other variables to a significant extent. In comparison with the Taylor rule, the reaction function under inflation targeting in an open economy responds to more information, particularly to foreign disturbances. Our findings also show that we can use the Taylor rules to predict exchange rates for seven CEE countries and to determine whether a currency is over- or undervalued and the tendency of real exchange rate using domestic and foreign inflation rates, output gaps and interest rate differentials changes. Nevertheless, reaping unbounded gains from arbitrage in traded goods is not possible in these seven CEE countries.

\section{CONCLUSIONS}

This paper applies nonlinear quantile unit root test with the Fourier function to test whether the Taylor rule predicted the exchange rate for Central and Eastern countries from January 1994 to December 2016. Traditional linear methods are inadequate for detecting series nonlinearity and cannot detect various smooth structural breaks of an unknown form. Our nonlinear quantile unit root test with the Fourier function cannot only provide more power than a standard univariate and linear unit root to reject 
a false null hypothesis of unit root behavior, but is flexible enough to allow for asymmetries in the dynamic behaviors of real exchange rates across a range of quantiles. Moreover, the method allows that shocks of different signs and sizes have different impacts on real exchange rate and accounts for the possible asymmetric adjustment of the real exchange rate towards its long-term equilibrium. The empirical evidence suggests that the real exchange rates based on the Taylor rules are well characterized in CEECs by a non-linear mean-reverting process which exhibits periods of structural breaks.

\section{REFERENCES}

Airaudo, M., Zanna, L. F., Interest Rate Rules, Endogenous Cycles and Chaotic Dynamics in Open Economies, "Journal of Economic Dynamics and Control”, 36, pp. 1566-1584, 2012.

Bacchetta, P., van Wincoop, E., Can Information Heterogeneity Explain the Exchange Rate Determination Puzzle?, “American Economic Review”, 96, pp. 552-576, 2006.

Bai, J., Perron, P., Estimating and Testing Linear Models with Multiple Structural Changes, "Econometrica", 66, pp. 47-78, 1998.

Bodenstein, M., Erceg, C. J., Guerrieri, L., Optimal Monetary Policy with Distinct Core and Headline Inflation Rates, "Journal of Monetary Economics", 55(Supplement), pp. 18-33, 2008.

Cheung, Y. W., Chinn, M. D., Pascual, A. G., Empirical Exchange Rate Models of the Nineties: Are Any Fit to Survive?, "Journal of International Money and Finance", 24(7), pp. 1150$-1175,2005$.

Chortareas, G. E., Kapetanios, G., Shin, Y., Nonlinear Mean Reversion in Real Exchange Rates, "Economics Letters", 77, pp. 411-417, 2002.

Clarida, R., Jordi, G., Mark, G., (1998) Monetary Policy Rules in Practice: Some International Evidence, "European Economic Review", 42, pp. 1033-1068, 1998.

Clarida, R., Jordi, G., Mark, G., Optimal Monetary Policy Rule in Open versus Closed Economies: An Integrated Approach, "American Economic Review”, 91, pp. 248-252, 2001.

Clarida, R., Waldman, D., Is Bad News about Inflation Good News for the Exchange Rate? [in:] Campbell, J. Y. (ed.), Asset Prices and Monetary Policy. University of Chicago Press, 2008.

Consolo, A., Favero, C. A., Monetary Policy Inertia: More a Fiction than a Fact?, "Journal of Monetary Economics", 56(6), pp. 900-906, 2009.

Dickey, D. A., Fuller, W. A., Likelihood Ratio Statistics for Autoregressive Time Series with a Unit Root, "Econometrica", 49, pp. 1057-1072, 1981.

Diebold, F. X., Mariano, R. S., Comparing Predictive Accuracy, "Journal of Business \& Economic Statistics", 13, pp. 253-263, 1995. 
Dolado, J. J., Maria-Dolores, R., Naveira, M., Are Monetary Policy Reaction Functions Asymmetric? The Role of Nonlinearity in the Phillips Curve, "European Economic Review", 49, pp. 485-503, 2005.

Enders, W., Lee, J., A Unit Root Test Using a Fourier Series to Approximate Smooth Breaks, "Oxford Bulletin of Economics and Statistics", 74, pp. 574-599, 2012.

Eng, Y. K., Wong, C. Y., Habibullah, M. S., Endogenous Structural Breaks and Real Exchange Rates Stationarity in Asia: Empirics and Theory, "Journal of Korea Trade", 16, pp. 23-42, 2012.

Engel, C.,West, K. D., Taylor Rules and the Deutschmark-Dollar Real Exchange Rate, "Journal of Money, Credit, and Banking", 38, pp. 1175-1194, 2006.

Engel, C., Nelson, C. M., Kenneth, D. W., Exchange Rate Models Are Not as Bad as You Think [in:] Acemoglu, D., Rogoff, K., Woodford, M. (eds.), NBER Macroeconomics Annual 2007, pp. 381-441, University of Chicago, 2008.

Engel, C., West, K. D., Accounting for Exchange Rate Variability in Present Value Models When the Discount Factor is Near One, "American Economic Review", 94, pp. 119-125, 2004.

Engel, C., West, K. D., Exchange Rates and Fundamentals, "Journal of Political Economy", 113, pp. 485-517, 2005.

Faust, J., Rogers, J. H., Wright, J. H., Exchange Rate Forecasting: The Errors We've Really Made, "Journal of International Economics", 60(1), pp. 35-59, 2003.

Frömmel, M., Garabedian, G., Schobert, F., Monetary Policy Rules in Central and Eastern European Countries, "Journal of Macroeconomics", 33, pp. 807-818, 2011.

Gali, J., Monetary Policy, Inflation, and the Business Cycle. Princeton University Press, 2008.

Gallant, R., On the Basis in Flexible Functional Form and an Essentially Unbiased Form: The Flexible Fourier Form, "Journal of Econometrics", 15, pp. 211-253, 1981.

Gerdesmeier, D., Roffia, B., Taylor Rules for the Euro Area: The Issue of Real-time Data, Discussion Paper Series 1: Economic Studies 2004,37, Deutsche Bundesbank, Research Centre, 2004.

Gerlach-Kristen, P., Is the MPC's Voting Record Informative about Future UK Monetary Policy?, "The Scandinavian Journal of Economics", 106(2), pp. 299-313, 2004.

Groen, J. J., The Monetary Exchange Rate Model as a Long-run Phenomenon, "Journal of International Economics" 52, pp. 299-319, 2000.

Judd, J. P., Rudebusch, G. D., Taylor's rule and the Fed, 1970-1997, "Economic Review", Federal Reserve Bank of San Francisco, 3, pp. 3-16, 1998.

Kapetanios, G., Shin, Y., Snell, A., Testing for a Unit Root in the Nonlinear STAR Framework, "Journal of Econometrics", 112, pp. 359-379, 2003.

Kilian, L., Taylor, M. P., Why Is It So Difficult to Beat the Random Walk Forecast of Exchange Rates?, "Journal of International Economics”, 60(1), pp. 85-107, 2003.

Kim, D., Perron, P., Unit Root Tests Allowing for a Break in the Trend Function under Both the Null and Alternative Hypotheses, "Journal of Econometrics", 148, pp. 1-13, 2009.

Kozichi, N., How useful are Taylor rules for monetary policy?, Federal Reserve Bank of Kansas, "Economic Review”, 2, pp. 5-33, 1999. 
Kwiatkowski, D., Phillips, P. C. B., Schmidt, P., Shin, Y., Testing the Null Hypothesis of Stationarity against the Alternative of a Unit Root, "Journal of Econometrics", 54, pp. 159-178, 1992.

Lee, J., Strazicich, M. C., Minimum LM Unit Root Test with Two Structural Breaks, "Review of Economics and Statistics", 63, pp. 1082-1089, 2003.

Li, H., Park, S. Y., Testing for a Unit Root in a Nonlinear Quantile Autoregression Framework, "Econometric Reviews", pp. 1-26, 2016.

Maddala, G. S., Kim, I.-M., Unit Roots, Cointegration, and Structural Change. Cambridge University Press, 1998.

Mark, N. C., Sul, D., Nominal Exchange Rates and Monetary Fundamentals: Evidence from a Small Post-Bretton Woods Panel, "Journal of International Economics", 53(1), pp. 29-52, 2001.

McGettigan, D., Moriyama, K., Noah Ndela Ntsama, J., Painchaud, F., Qu, H., Steinberg, C., Monetary Policy in Emerging Markets: Taming the Cycle, IMF Working Paper no. 13/96, 2013.

Meese, R. A., Rogoff, K., Empirical Exchange Rate Models of the Seventies: Do They Fit Out of Sample?, "Journal of International Economics”, 14, pp. 3-24, 1983a.

Meese, R. A., Rogoff, K., The Out-of-Sample Failure of Empirical Exchange Rate Models: Sampling Error or Misspecification? University of Chicago Press, 1983b.

Mehra, Y. P., Sawhney, B., Inflation Measure, Taylor Rules, and the Greenspan-Bernanke Years, "Economic Quarterly”, 96, pp. 123-151, 2010.

Molodtsova, T., Papell, D. H., Out-of-sample Exchange Rate Predictability with Taylor Rule Fundamentals, "Journal of International Economics", 77(2), pp. 167-180, 2009.

Newey, W. K., West, K. D., A Simple Positive Definite Heteroskedasticity and Autocorrelation Consistent Covariance Matrix, "Econometrica", 55, pp. 703-708, 1987.

Ng, S., Perron, P., Lag Length Selection and the Construction of Unit Root Tests with Good Size and Power, "Econometrica", 69, pp. 1519-1554, 2001.

Nobay, A. R., Peel, D., Optimal Discretionary Monetary Policy in a Model of Asymmetric Central Bank Preferences, "Economic Journal", 113, pp. 657-665, 2003.

Nunes, L., Newbold, P., Kuan, C., Testing for Unit Roots with Breaks: Evidence on the Great Crash and the Unit Root Hypothesis Reconsidered, "Oxford Bulletin of Economics and Statistics", 59, pp. 435-448, 1997.

Perron, P., The Great Crash, the Oil Price Shock and the Unit Root Hypothesis, "Econometrica", 57(6), pp. 1361-1401, 1989.

Phillips, P. C. B., Perron, P., Testing for a Unit Root in Time Series Regression, "Biometrica", 75, pp. 335-346, 1988.

Romer, D., Advanced Macroeconomics (4, Revised Ed.). McGraw Hill Higher Education, London/US, 2011.

Ruge-Murcia, F. J., Inflation Targeting under Asymmetric Preferences, "Journal of Money, Credit and Banking", 35, pp. 763-785, 2003.

Sarno, L., Real Exchange Rate Behavior in the Middle East: A Re-examination, "Economics Letters", 66, pp. 127-136, 2000. 
Schmidt, P., Phillips, P. C. B., LM Test for a Unit Root in the Presence of Deterministic Trends, "Oxford Bulletin of Economics and Statistics", 54, pp. 257-287, 1992.

Surico, P., The Fed's Monetary Policy Rule and U.S. Inflation: The Case of Asymmetric Preferences, "Journal of Economic Dynamics and Control", 31, pp. 305-324, 2007.

Svensson, L. E. O., Open Economy Inflation Targeting, "Journal of International Economics", 50, pp. 155-183, 2000.

Taylor, J. B., Discretion versus Policy Rules in Practice, "Carnegie-Rochester Conference Series on Public Policy”, 39, pp. 195-214, 1993.

Taylor, M. P., Peel, D. A., Non-linear Adjustment, Long-run Equilibrium and Exchange Rate Fundamentals, "Journal of International Money and Finance", 19, pp. 33-53, 2000.

West, K. D., Asymptotic Inference about Predictive Ability, "Econometrica”, 64, pp. 10671084, 1996.

Received: April 2015, revised: May 2017 